\title{
A comparative study of lung function test between physically trained and untrained adults
}

\author{
Sridip Chatterjee ${ }^{1}$, Aloke Sen Borman ${ }^{2}$, Aparup Konar ${ }^{3}$, Samiran Mondal ${ }^{4}$ \\ ${ }^{1}$ Department of Physical Education, Jadavpur University, Kolkata - 700032, West Bengal, India \\ ${ }^{2}$ Seva Bharati Mahavidyalaya, Department of Physical Education, Kapgari - 721505, Paschim Midnapore, West Bengal, India \\ ${ }^{3}$ Director of Physical Instruction, Office of the Sports Board, Jadavpur University, Kolkata - 700032, West Bengal, India \\ ${ }^{4}$ Department of Physical Education, Vinaya Bhavana, Visva Bharati, Santiniketan - 731235, West Bengal, India
}

\section{Email address:}

sritun14@gmail.com (S. Chatterjee), dralokesenorman@gmail.com (A. S. Borman), kaparup@gmil.com (A. Konar), msamiran@rediffmail.com (S. Mondal)

\section{To cite this article:}

Sridip Chatterjee, Aloke Sen Borman, Aparup Konar, Samiran Mondal. A Comparative Study of Lung Function Test between Physically Trained and Untrained Adults. American Journal of Sports Science. Vol. 2, No. 5, 2014, pp. 127-130. doi: 10.11648/j.ajss.20140205.14

\begin{abstract}
Background: The maximum lung function for human being reached around the age of 20-25 years. Studies on lung function indicated a progressive age-related functional change of the respiratory physiology. Regular physical activity throughout the life may delay this deterioration of lung function. Objective of the study: The present study was designed to observe the effect of aging on lung function induced by regular physical activity. Methods: Respiratory function was tested by digital spirometer. 479 persons (Male: 246 and Female: 233) ages between 20-70 years were examined at the department labortory, Jadavpur University, Kolkata. 79 persons were excluded from the study due to acute or chronic respiratory disorders and the history of smoking. All the subject were allotted in the five age category (20-29 yrs; 30-39 yrs;40-49 yrs; 50-59 yrs and 60-70 yrs) to observe the age related changes between the trained (male: 100 and female:100) and untrained (male: 100 and female:100) persons. Mean, Standard deviation and ' $t$ ' test were done to calculate the statistical significance and made a valid conclusion. Result: A slow progressive age related decline were observed in trained group compared to untrained in all the age category for both male and female. Conclusion: From the present study it can be concluded that regular physical activity may delay the age related decline of lung function for all the age groups and promote healthy aging.
\end{abstract}

Keywords: Aging, Spirometry, Exercise

\section{Introduction}

During the first two decades of life, the lungs undergo a phase of growth and maturation [1]. The maximum lung function reached around the age of 20-25 years. After birth the individual lungs are continuously being exposed to particles in the air, including smoke, pollen, dust and microorganisms. These external hazards may limit the physiological potentialities of the lungs. Aging is associated with a progressive decline in lung performance. The respiratory system undergoes many physiological modifications during aging are: a decrease in the static elastic recoil of the lung, a decrease in compliance of the chest wall, a decrease in the strength of respiratory muscles, the amount of oxygen diffusing from the air sacs into the blood decreases, the rate of air flow through the airways slowly declines and the numbers of alveoli decreases [1, 2].

Exercise when performed regularly has benefits on the various systems of the body and maintains an overall health status of the individual. Regular physical activity has proved to be beneficial for the human body and the lungs are no exception [3-7]. Pulmonary function is a long-term predictor for overall survival rates in both genders [7]. Efficient lung function is a preventive measure and positively influence by exercise habits. The pulmonary functional capacities of normal sedentary individuals have been studied extensively in India [4]. Sedentary lifestyles could be associated with less efficient pulmonary function [7].

Hence, the present study was undertaken with a view to observe the pattern of progressive age related changes of lung function in different age group and how regular 
physical activity habit influence the pattern compared to age-sex matched sedentary individuals.

\section{Methods}

In the present study survey cum experimental design was adopted. Comprehensive respiratory health check up cum awareness camp was jointly organized by the department of physical education, Jadavpur University and Cipla Ltd., Kolkata, India. Total 246 male and 233 female ages between 20 years to 70 years from Jadavpur University community were tested for lung function (spirometry) in the physical education department laboratory. All the subjects willingly register their names to attain the said camp and signed the inform consent form. All the subjects were interviewed and instructed to complete a general health-physical activity form with a view to allotted the subjects in the trained (exerciser) and untrained (non-exerciser) group in the five different age category: 20-29 years; 30-39 years; 40-49 years; 50-59 years and 60-69 years. The subjects in the exercise group maintain a regular exercise habit (3-4 days / weak) for minimum period of five years. The subjects in the non-exercise group basically lead a sedentary life style. 27 male and 19 female were excluded from the study due to acute or chronic respiratory disorders. Another 19 male and 14 female were excluded due to the habit of smoking. Finally 100 male \& 100 female in the trained group and 100 male \& 100 female in the untrained group were considered for analysis of data. Mean, standard deviation and simple percentage from the mean value were calculated. The difference between the means were compared separately (trained vs untrained group)
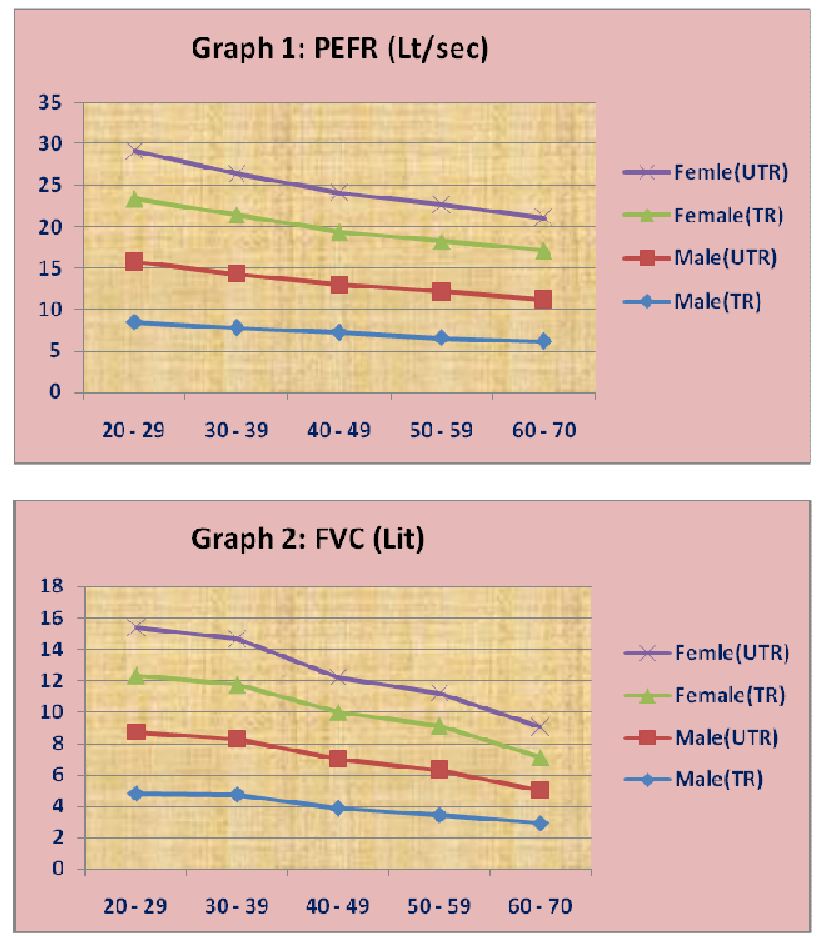

by using student's ' $t$ ' test for the five different age groups. The mean differences were considered significant when the $p$ values were $<0.05$.

\section{Spirometry (Lung Function Variables)}

Peak Expiratory Flow Rate (PEFR), Forced Vital Capacity (FVC), Forced Expiratory Volume in $1 \& 6 \mathrm{Sec}$ $\left(\mathrm{FEV}_{1}, \mathrm{FEV}_{6}\right)$, Ratio of $\mathrm{FEV}_{1}$ and $\mathrm{FVC}\left(\mathrm{FEV}_{1} / \mathrm{FVC}\right)$ and Forced expiratory flow $25 \%-75 \%\left(\mathrm{FEF}_{25-75}\right)$ were measured by using "digital spirometer" (DT Spiro, Mestros Medline System Ltd., Model No. PoP-10.8). Instrument was calibrated properly before each experimental session and best of two trials were considered as final measurement.

\section{Results}

Data relating to lung function test of trained and untrained group for both male and female in five different age category are presented in table No. 1. It appears that slow progressive age related decline were observed in trained group (exerciser) compared to untrained (nonexerciser) in five different age category for both male and female. Simple percentages were calculated from the mean value for the entire age category and presented in Table no. 1 and graph no. 1 to 6 , to see the quantitative changes between trained and untrained group. Single star $(*)$ in the table no. 1 denote $\mathrm{P}<0.05$, double star $(* *)$ denote $\mathrm{P}<0.01$ and triple star $(* * *)$ denote $\mathrm{P}<0.001$.
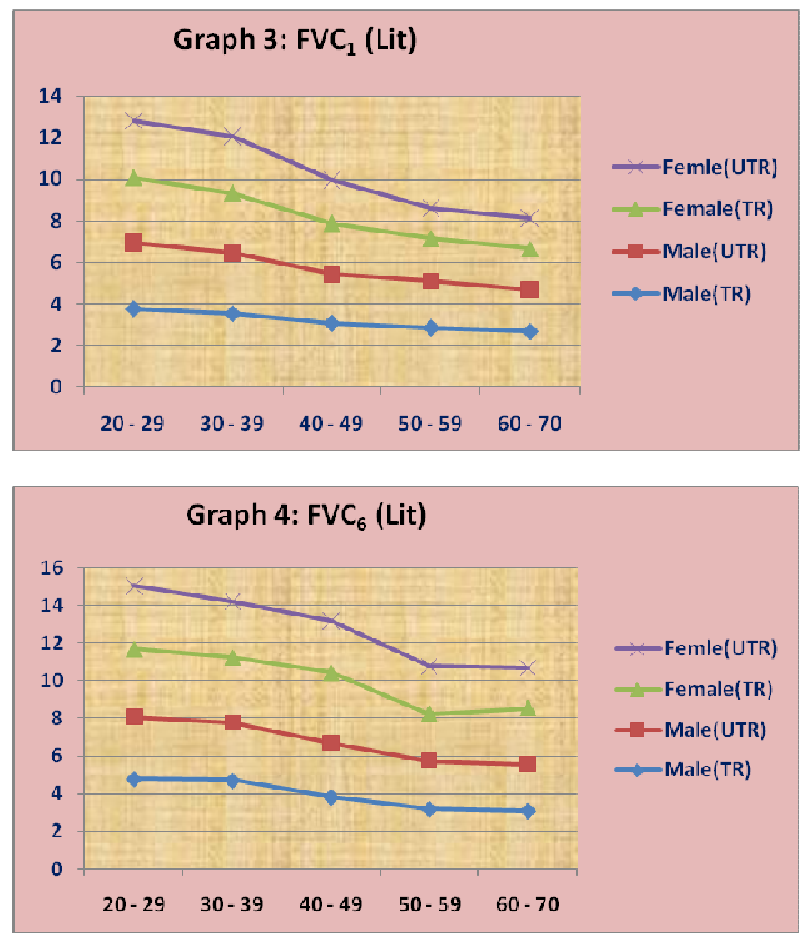
Table 1. Status of Lung Function Variables for Trained and Untrained Group

\begin{tabular}{|c|c|c|c|c|c|c|}
\hline \multirow{3}{*}{ Age group } & \multicolumn{2}{|l|}{ Male } & \multirow{3}{*}{$\%$ Change } & \multicolumn{2}{|l|}{ Female } & \multirow{3}{*}{$\%$ Change } \\
\hline & Trained N= 20 & \multirow{2}{*}{$\begin{array}{l}\text { Untrained N= 20 } \\
\text { Mean } \pm \text { SD }\end{array}$} & & \multirow{2}{*}{$\begin{array}{l}\text { Trained N= 20 } \\
\text { Mean } \pm \text { SD }\end{array}$} & \multirow{2}{*}{$\begin{array}{l}\text { Untrained } \mathbf{N}=\mathbf{2 0} \\
\text { Mean } \pm \text { SD }\end{array}$} & \\
\hline & Mean \pm SD & & & & & \\
\hline \multicolumn{7}{|c|}{ PEFR (Lit/Sec) } \\
\hline $20-29$ & $8.47 \pm 2.02$ & $7.33 \pm 1.83$ & $13.46^{*}$ & $7.65 \pm 1.54$ & $5.71 \pm 1.29$ & $25.36^{* * *}$ \\
\hline $30-39$ & $7.79 \pm 2.30$ & $6.54 \pm 1.57$ & $16.05^{*}$ & $7.11 \pm 1.81$ & $4.96 \pm 1.03$ & $30.24 * *$ \\
\hline $40-49$ & $7.25 \pm 1.83$ & $5.83 \pm 0.99$ & $19.59 *$ & $6.23 \pm 0.78$ & $4.77 \pm 0.81$ & $23.44 * *$ \\
\hline $50-59$ & $6.55 \pm 1.47$ & $5.68 \pm 0.68$ & 13.288 & $5.98 \pm 0.54$ & $4.45 \pm 0.87$ & $25.58 * *$ \\
\hline $60-70$ & $6.16 \pm 1.19$ & $5.07 \pm 1.23$ & $17.96^{*}$ & $5.87 \pm 0.93$ & $3.98 \pm 0.58$ & $32.20 * *$ \\
\hline \multicolumn{7}{|l|}{ FVC (Lit) } \\
\hline $20-29$ & $4.81 \pm 1.27$ & $3.91 \pm 1.16$ & $18.71^{*}$ & $3.61 \pm 1.09$ & $3.08 \pm 1.19$ & $14.68^{*}$ \\
\hline $30-39$ & $4.75 \pm 1.12$ & $3.56+1.15$ & $25.05 * *$ & $3.42 \pm 1.21$ & $2.97 \pm 1.11$ & $13.16^{*}$ \\
\hline $40-49$ & $3.86 \pm 1.36$ & $3.16+1.24$ & $18.13^{*}$ & $2.97 \pm 1.21$ & $2.23 \pm 0.73$ & $24.92 * *$ \\
\hline $50-59$ & $3.43 \pm 1.26$ & $2.90+1.38$ & $15.45^{*}$ & $2.79 \pm 1.24$ & $2.10 \pm 0.81$ & $24.73 * *$ \\
\hline $60-70$ & $2.90 \pm 1.04$ & $2.12+1.28$ & 7.42 & $2.10 \pm 0.97$ & $1.93 \pm 0.87$ & 8.09 \\
\hline \multicolumn{7}{|l|}{$\mathrm{FEV}_{1}$ (Lit) } \\
\hline $20-29$ & $3.76 \pm 1.03$ & $3.18 \pm 1.37$ & $15.43 *$ & $3.16 \pm 1.29$ & $2.74 \pm 1.13$ & 13.298 \\
\hline $30-39$ & $3.53 \pm 1.14$ & $2.91 \pm 1.41$ & $17.56^{*}$ & $2.92 \pm 1.24$ & $2.70 \pm 1.08$ & 7.53 \\
\hline $40-49$ & $3.07 \pm 1.23$ & $2.33 \pm 1.07$ & $24.10 * *$ & $2.48 \pm 1.11$ & $2.07 \pm 0.77$ & $16.53^{*}$ \\
\hline $50-59$ & $2.85 \pm 0.87$ & $2.23 \pm 0.78$ & $21.75^{* *}$ & $2.06 \pm 0.67$ & $1.48 \pm 0.39$ & $28.15^{* *}$ \\
\hline $60-70$ & $2.68 \pm 0.67$ & $1.99+0.49$ & $25.75 * *$ & $1.98 \pm 0.97$ & $1.46 \pm 0.43$ & $26.26^{* *}$ \\
\hline \multicolumn{7}{|l|}{$\mathrm{FEV}_{6}(\mathrm{Lit})$} \\
\hline $20-29$ & $4.79 \pm 1.05$ & $3.28 \pm 1.23$ & $31.52 * *$ & $3.61 \pm 1.12$ & $3.37 \pm 1.31$ & 6.64 \\
\hline $30-39$ & $4.71 \pm 1.15$ & $3.09 \pm 1.33$ & $34.39 * *$ & $3.45 \pm 1.05$ & $2.97 \pm 0.79$ & $19.73 *$ \\
\hline $40-49$ & $3.83 \pm 0.82$ & $2.89 \pm 0.87$ & $24.54 *$ & $3.50 \pm 0.98$ & $2.77 \pm 0.57$ & $19.71 *$ \\
\hline $50-59$ & $3.19 \pm 0.77$ & $2.53 \pm 0.49$ & $20.68^{*}$ & $2.53 \pm 0.76$ & $2.53 \pm 0.47$ & $14.81 *$ \\
\hline $60-70$ & $3.10 \pm 0.49$ & $2.47 \pm 0.57$ & 20.328 & $2.97 \pm 0.93$ & $2.13 \pm 0.39$ & $15.81 *$ \\
\hline \multicolumn{7}{|c|}{ FEV1/FVC (\%) } \\
\hline $20-29$ & $83.4 \pm 7.78$ & $76.7 \pm 8.23$ & 8.03 & $82.8 \pm 8.15$ & $78.0 \pm 7.79$ & 5.79 \\
\hline $30-39$ & $82.10 \pm 8.37$ & $75.47 \pm 8.54$ & 8.07 & $81.23 \pm 7.93$ & $76.91 \pm 6.89$ & 5.32 \\
\hline $40-49$ & $79.25 \pm 6.87$ & $73.59 \pm 6.42$ & $7.14 *$ & $79.50 \pm 7.22$ & $75.30 \pm 7.44$ & $5.28 *$ \\
\hline $50-59$ & $78.07 \pm 7.11$ & $71.53 \pm 8.37$ & $8.38 *$ & $78.74 \pm 6.31$ & $75.00 \pm 7.41$ & 4.75 \\
\hline $60-70$ & $77.7 \pm 9.17$ & $71.47 \pm 5.23$ & 8.02 & $78.1 \pm 5.04$ & $74.23 \pm 6.67$ & 4.96 \\
\hline \multicolumn{7}{|c|}{$\mathrm{FEV}_{25-75}(\mathrm{Lit} / \mathrm{Sec})$} \\
\hline $20-29$ & $4.96 \pm 1.51$ & $3.60 \pm 1.03$ & $27.41 * *$ & $4.01 \pm 1.43$ & $3.12 \pm 1.03$ & $22.19 * *$ \\
\hline $30-39$ & $4.73 \pm 1.71$ & $3.19 \pm 1.11$ & $32.56^{* * * *}$ & $3.95 \pm 1.28$ & $2.71 \pm 0.49$ & $31.39 * *$ \\
\hline $40-49$ & $3.81 \pm 0.79$ & $2.89 \pm 0.58$ & $24.15 * *$ & $3.71 \pm 1.01$ & $2.19 \pm 0.78$ & $40.97 * * *$ \\
\hline $50-59$ & $3.11 \pm 0.29$ & $2.67 \pm 0.58$ & $14.15^{*}$ & $3.43 \pm 0.79$ & $2.04 \pm 0.55$ & $40.52 * * *$ \\
\hline $60-70$ & $3.09 \pm 0.47$ & $2.50 \pm 0.73$ & $19.09 *$ & $2.81 \pm 0.67$ & $1.87 \pm 0.52$ & $33.45 * *$ \\
\hline
\end{tabular}
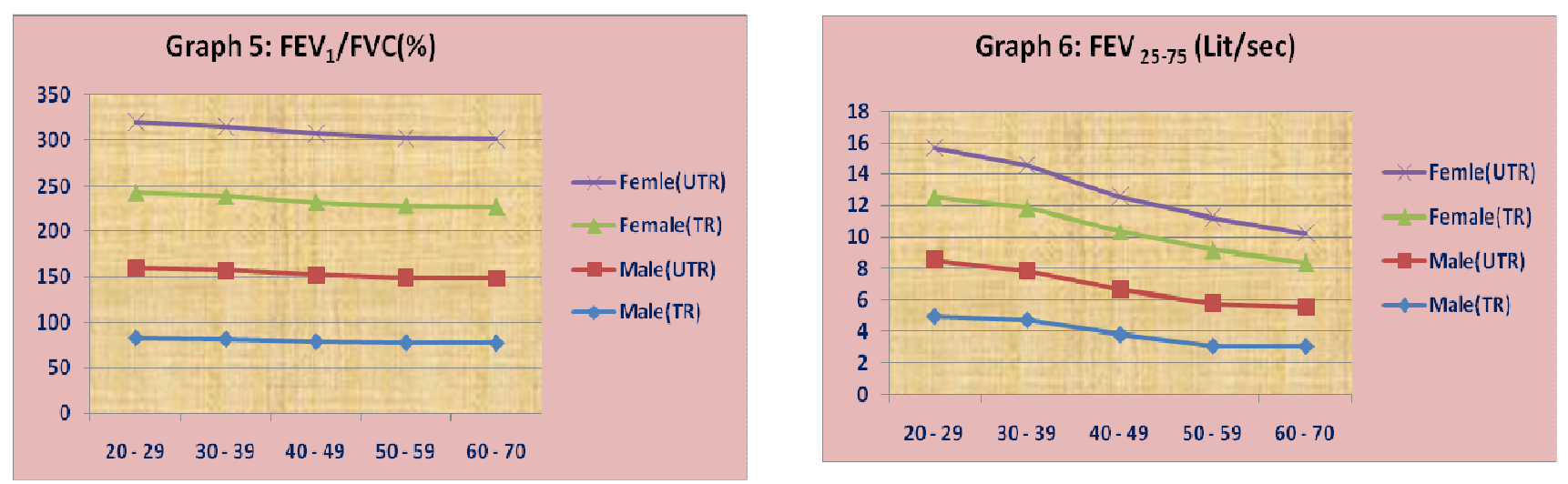


\section{Discussion}

Age is an unmodifiable risk factor for decrease respiratory function. During childhood and adolescence there is a natural rise in lung function, after which it declines gradually. Regular exercise habit may be a preventive strategy for healthy functioning of the lungs. Previous investigations on lung function variables reported that all the sportspersons or exerciser had a higher value of lung functions compared to the sedentary controls [7-11]. Thus the purpose of the present study was to examine and compare the age related changes of lung function variables in trained and untrained subjects. The results of the present study showed that exercise habit throughout the life had a positive influence on lung function as compared to age-sex matched sedentary controls.

Some limitations of our study could be understood. Firstly, the absolute assessment of physical activity was difficult, so only leisure time physical activity was considered in this study. Secondly we did not able to control the individual life style and social factors which may influence the results.

From the above discussion it may be interpreted that: (i) Involvement in certain physical activities or sports develop respiratory muscle strength and static elastic recoil pressure of the lung [1, 10]. (ii) Exercise is associated with an increased in diaphragm thickness and respiratory muscle mass [6]. (iii) Efficient functioning of the alveoli and gaseous exchange between lungs and blood vessels. (iv) Regular physical activity or exercise positively influences the stretch receptors in the air passages and lungs and chemoreceptors function in the body [14]. (v) Regular forceful inspiration and expiration for prolonged period during exercise leads to strengthening of the respiratory muscles. This helps the lungs to inflate and deflate maximally. This maximum inflation and deflation is an important physiological stimulus for the release of surfactant [14].

\section{Conclusion}

From the present study it can be concluded that regular physical activity may be a strategy to delay the age related decline of respiratory physiological function for all the age groups and thus promote healthy aging. Therefore, exercise is a nonpharmacological complementary alternative method recommended for efficient functioning of the lung throughout the life.

\section{References}

[1] J.P. Janssens, J.C. Pache, L.P. Nicod. Physiological changes in respiratory function associated with ageing. Eur Respir J. 1999, 13: 197-205.

[2] J.P. Janssens. Aging of the respiratory system: Impact on pulmonary function tests and adaptation to exertion. Clin Chest Med. 2005, $26:$ 469-484.

[3] P. Hamilton, G.M. Andrew. Influence of growth and athletic training on heart and lung functions. Eur J Appl Physiol Occup Physiol. 1976; 36 (1) : 27-38.

[4] A.K. Ghosh, A. Ahuja, G.L. Khanna. Pulmonary capacities of different groups of sportsmen in India. Brit. J. Sports Med. 1985,19 (4) : 232-234.

[5] S.M. Hulke, M.S. Phatak. Effect of endurance training on lung function: a longitudinal study. Int J Biol Med Res. 2011, 2 (1) : 443-446.

[6] C. Garber, F.D. McCool. Respiratory muscle strength in the physically active elderly. Lung. 2007, $185:$ 315-320.

[7] S. Prakash, S. Meshram, U. Ramtekkar. Athletes, Yogi and individuals with sedentary life styles; Do their lung functions differ? Indian J Physiol Pharmacol. 2007, 5 (1) : 76-80.

[8] P.K. Mehrotra, N. Varma, S. Tiwari, P. Kumar. Pulmonary functions in Indian sportsmen playing different sports. Indian J Physiol Pharmacol. 1998, 42 (3) : 412-6.

[9] M.R. Ide, M.A.V. Belini, F.A. Caromano. Effects of an aquatic versus non-aquatic respiratory exercise program on the respiratory muscle strength in healthy aged persons. Clinics. 2005, 60 (2) : 151-158.

[10] Y.J. Cheng, C.A. Macera, C.L. Addy, F.S. Sy, D. Weiland, S.N. Blair. Effects of physical activity on exercise tests and respiratory function. Br J Sports Med. 2003, 37: 521-528.

[11] K.R. Vincent, R.W. Braith, R.A. Feldman, H.E. Kallas, D.T. Lowenthal. Improved cardiorespiratory endurance following 6 months of resistance exercise in elderly men and women. Arch Intern Med. 2002, $162:$ 673-678.

[12] A. Rossi, A. Ganassini, C. Tantucci, V. Grassi. Aging and the respiratory system. Aging (Milano). 1996, 8 (3) : 143-61.

[13] R.J. Shephard. Aging, physical activity and health. Human Kinetics. 1997.

[14] L. Shashikal, R. Sarath. Effect of exercise on pulmonary function test. Indian journal of Fundamental and Applied Life Sciences. 2011, 1(3): 230-231. 